\title{
Fragmentation of Protonated Oligoalanines: Amide Bond Cleavage and Beyond
}

\author{
Alex G. Harrison and Alex B. Young \\ Department of Chemistry, University of Toronto, Toronto, Ontario, Canada
}

The fragmentation reactions of the singly-protonated oligoalanines trialanine to hexaalanine have been studied using energy-resolved mass spectrometry in $\mathrm{MS}^{2}$ and $\mathrm{MS}^{3}$ experiments. The primary fragmentation reactions are rationalized in terms of the $b_{x}-y_{z}$ pathway of amide bond cleavage which results in formation of a proton-bound complex of an oxazolone and a peptide/amino acid; on decomposition of this complex the species of higher proton affinity preferentially retains the proton. For protonated pentaalanine and protonated hexaalanine the major primary fragmentation reaction involves cleavage of the C-terminal amide bond to form the appropriate $\mathrm{b}$ ion. The lower mass $\mathrm{b}$ ions originate largely, if not completely, by further fragmentation of the initially formed $\mathrm{b}$ ion. $\mathrm{MS}^{3}$ energy-resolved experiments clearly show the fragmentation sequence $b_{n} \rightarrow b_{n-1} \rightarrow b_{n-2}$. A more minor pathway for the alanines involves the sequence $b_{n} \rightarrow a_{n} \rightarrow b_{n-1} \rightarrow b_{n-2}$. The $a_{5}$ ion formed from hexaalanine loses, in part, $\mathrm{NH}_{3}$ to begin the sequence of fragmentation reactions $a_{5} \rightarrow a_{5}^{*} \rightarrow a_{4}^{*} \rightarrow a_{3}^{*}$ where $a_{n}^{*}=a_{n}-N H_{3}$. The $a_{3}^{*}$ ion also is formed from the $b_{3}$ ion by the sequence $b_{3} \rightarrow a_{3} \rightarrow a_{3}^{*}$ with the final step being sufficiently facile that the $a_{3}$ ion is not observed with significant intensity in CID mass spectra. A cyclic structure is proposed for the $\mathrm{a}_{3}^{*}$ ion. (J Am Soc Mass Spectrom 2004, 15, 1810-1819) (C) 2004 American Society for Mass Spectrometry

W ith the advent of soft ionization techniques such as electrospray ionization (ESI) [1-3] and matrix-assisted laser desorption-ionization (MALDI) $[4,5]$ which efficiently ionize by protonation a wide variety of peptides and proteins, tandem mass spectrometry $[6,7]$ has become a method of significant importance for the sequencing of peptides through collision-induced dissociation (CID) studies. As a result, the main types of fragmentation reactions occurring are well-established [8-11], at least in a phenomenological sense and are outlined in Scheme 1. A major mode of fragmentation in many cases involves cleavage of an amide bond in the protonated peptide. When the charge is retained by the C-terminus fragment migration of a labile hydrogen from the $\mathrm{N}$ terminus neutral fragment occurs to form a protonated amino acid $\left(y_{1}\right)$ or peptide $\left(y_{n}\right)[12,13]$. When the charge remains on the $\mathrm{N}$-terminus fragment, a neutral amino acid or peptide is eliminated and $b_{n}$ ions are formed. Although these $b_{n}$ ions were initially considered to be acylium ions $[8,10,11]$, extensive experimental and theoretical studies [14-19] have shown that, in many cases, the $b_{n}$ ions have protonated oxazolone structure as shown in Scheme 2 formed by cyclization involving

Published online November 2, 2004

Address reprint requests to Dr. A. G. Harrison, Department of Chemistry, University of Toronto, 80 George Street, Toronto, Ontario M5S 3H6, Canada. E-mail: aharriso@chem.utoronto.ca the carbonyl function next-nearest to the amide bond being ruptured. In several cases where there are more reactive side-chain groups in the peptide, alternative cyclic structures are formed by interaction with sidechain functionality as the amide bond cleavage occurs $[20,21]$.

Although the fragmentation reactions of $b_{2}$ ions have been studied in some detail [14, 18, 22, 23], the fragmentation reactions of larger $b$ ions have seen less study [15] and the fragmentation of $a_{n}$ ions have seen even less study. A related question is whether, for larger protonated peptides, the lower mass $b$ ions are formed directly by fragmentation of the protonated peptide or are secondary fragmentation products. In the present work we have undertaken a detailed study of protonated oligoalanines with two goals in mind, first, to determine as far as possible the relative importance of primary cleavage of the different amide bonds in the peptide and, second, to elucidate further the fragmentation pathways of the various $b$ ions and a ions which are observed in the CID mass spectra. The fragmentation reactions of various protonated oligoalanines have seen extensive study [15, 24-29] although little attention has been paid to the question of the relative propensity for cleavage of the different amide bonds, and the secondary fragmentation reactions have seen only limited attention [15]. The oligoalanines are of particular interest in the present context because Paizs and Suhai [29] have recently reported ab initio calculations of the proton affinities of the oxazolones and amino acids/ peptides involved in the fragmentation of protonated 


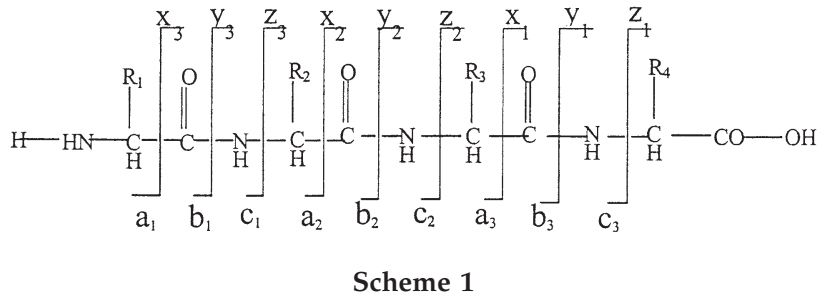

pentaalanine which allows one to relate the fragmentation reactions observed for the various oligoalanines to the relative thermochemistry involved.

\section{Experimental}

Initial CID studies were carried out using an electrospray/quadrupole mass spectrometer (VG Platform, Micromass, Manchester, UK) with CID in the interface between the atmospheric pressure source and the quadrupole mass analyzer, so-called cone-voltage CID. It has been clearly established [30-34] that, by varying the field in this interface region, energy-resolved mass spectra [35] similar to those obtained by variable lowenergy CID in quadrupole cells can be obtained. The results of these cone-voltage CID experiments are presented in the following as breakdown graphs expressing the percentage of total ion signal as a function of the cone voltage. $\mathrm{MS}^{2}$ and $\mathrm{MS}^{3}$ experiments were also carried out using an electrospray/quadrupole/time-offlight (QqTOF) mass spectrometer (QStar, MDS Sciex, Concord, Canada). In the $\mathrm{MS}^{3}$ experiments, CID in the interface region produced fragment ions; those of interest being mass-selected by the first quadrupole mass analyzer $(Q)$ to undergo collisional activation in the quadrupole collision cell (q) with the ionic fragmentation products being analyzed by the time-of-flight analyzer [36, 37]. By varying the collision energy in the quadrupole cell, breakdown graphs for selected fragment ions were obtained under multiple collision conditions.

Ionization was by electrospray on both instruments. For the single quadrupole the peptide was dissolved in $1: 1 \mathrm{CH}_{3} \mathrm{CN} / 1 \%$ formic acid and introduced into the source at a flow rate of $30 \mu \mathrm{L} \mathrm{min}{ }^{-1}$ with nitrogen as both nebulizing and drying gas. For the QTOF instrument the peptide was dissolved in 1:1 $\mathrm{CH}_{3} \mathrm{OH} / 0.1 \%$ formic acid and introduced into the source at a flow rate of $80 \mu \mathrm{L} \mathrm{min}{ }^{-1}$. Nitrogen was used as nebulizing gas, drying gas and collision gas in the quadrupole cell.

All peptide samples were obtained from BACHEM Biosciences (King of Prussia, PA) and were used as received.

\section{Results and Discussion}

The detailed mechanism of amide bond cleavage in protonated peptides has not been definitively estab-
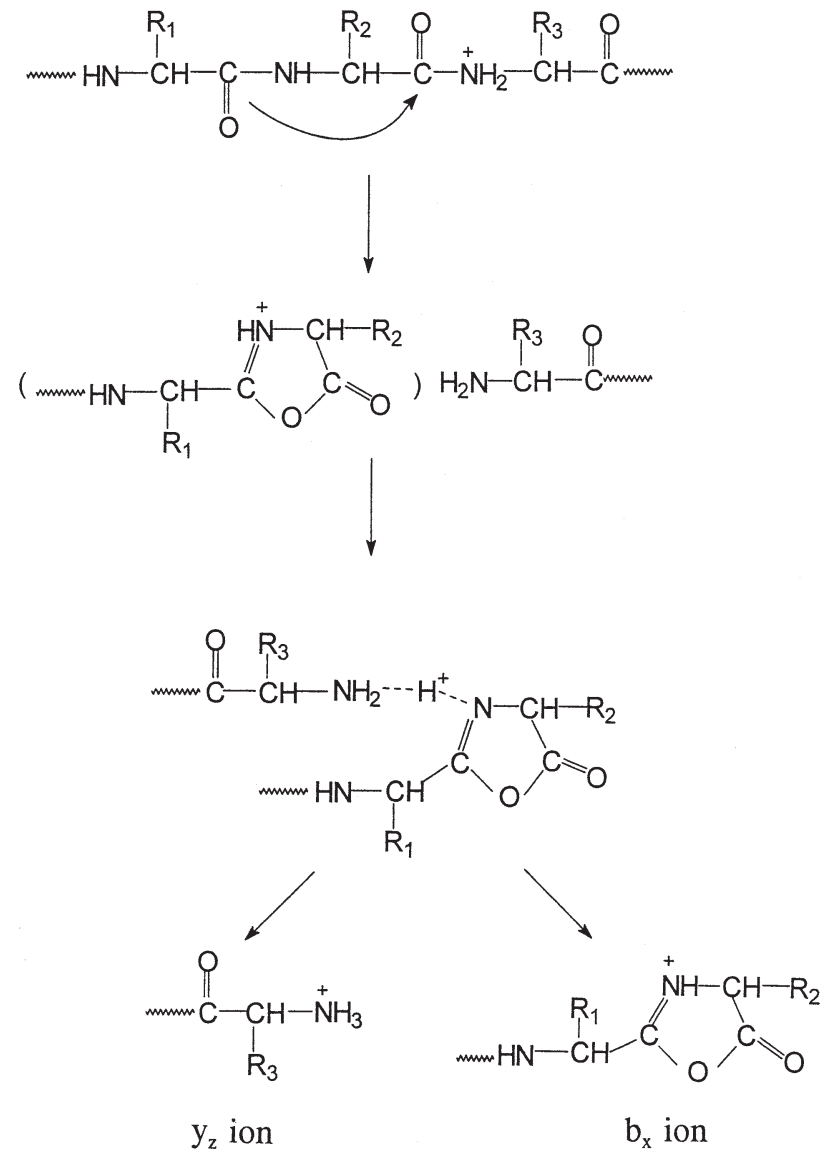

Scheme 2

lished although there is increasing evidence [29, $38-41]$ that fragmentation occurs from the amide $\mathrm{N}$-protonated species to form, at low internal energies, a proton-bound complex of an oxazolone and a truncated peptide or amino acid as illustrated in Scheme 2, the so-called $b_{x}-y_{z}$ pathway [41]. The fragmentation of such a proton-bound complex should be determined, largely by the relative proton affinities of the oxazolone and the peptide/amino acid, with that having the greater proton affinity being preferentially formed as the ionic species. The results of the present study will be interpreted in terms of the pathway of Scheme 2 and, indeed, provide support for the pathway.

\section{Trialanine}

The CID mass spectra of protonated trialanine obtained at three collision energies in the quadrupole collision cell are presented in Table 1. At the lowest collision energy only the $b_{2}$ fragment ion is observed indicating preferred fragmentation of the C-terminal amide bond. That the $b_{2}$ ion should be formed rather than the $y_{1}$ ion is in agreement with the relative proton affinities, that for the neutral $b_{2}$ oxazolone being $222.3 \mathrm{kcal} \mathrm{mol}^{-1}$ compared with $214.6 \mathrm{kcal} \mathrm{mol}^{-1}$ for alanine [29]. With increasing collision energy fragmentation of the $b_{2}$ ion 
Table 1. CID mass spectra of protonated trialanine

\begin{tabular}{rcccc}
\hline & & \multicolumn{3}{c}{ Collision energy } \\
\cline { 3 - 5 } $\mathrm{m} / \mathrm{z}$ & Ion & $6 \mathrm{eV}$ & $10 \mathrm{eV}$ & $14 \mathrm{eV}$ \\
\hline \hline 232 & $\mathrm{MH}^{+}$ & 100 & 55.9 & 10.1 \\
214 & $-\mathrm{H}_{2} \mathrm{O}$ & & 2.1 & 1.1 \\
161 & $\mathrm{y}_{2}$ & & 8.4 & 21.8 \\
143 & $\mathrm{~b}_{2}$ & 23.6 & 100 & 100 \\
115 & $\mathrm{a}_{2}$ & & 11.1 & 37.4 \\
90 & $\mathrm{y}_{1}$ & & & 2.1 \\
\hline
\end{tabular}

to the $a_{2}$ ion is observed as well as formation of the $y_{2}$ ion arising from cleavage of the N-terminal amide bond. Laskin and co-workers [26-28] have examined the fragmentation of protonated trialanine by surfaceinduced dissociation (SID) and by multiple-collision activation (SORI) using Fourier transform/ion cyclotron resonance (FT/ICR) mass spectrometry. Our present results are in best agreement with their SID spectrum, particularly with respect to the intensity of the $y_{2}$ ion. As they have noted [26], multiple-collision activation in FT/ICR discriminated against processes of higher critical reaction energy, in this case formation of the $\mathrm{y}_{2}$ ion.

\section{Tetraalanine}

The CID mass spectra of protonated tetraalanine at three collision energies are given in Table 2 while the breakdown graph obtained by cone-voltage CID is presented in Figure 1. The breakdown graph for the $b_{3}$ ion obtained on the QTOF instrument is presented in Figure 2. Clearly, the $b_{3}$ and $y_{2}$ ions are the major primary fragmentation products. An earlier metastable ion study [15] of the fragmentation of protonated tetraalanine produced by fast atom bombardment (FAB) showed $\mathrm{y}_{2}(100), \mathrm{b}_{3}(52)$, and $-\mathrm{H}_{2} \mathrm{O}(14)$. It is clear that the majority, if not all, of the $b_{2}$ ion arises by further fragmentation of the $b_{3}$ ion; this is in agreement with the conclusions of Laskin et al. [27]. (We cannot preclude the possibility that some of the $b_{2}$ ion arises by direct fragmentation of the central amide bond at high

Table 2. CID mass spectra of protonated tetraalanine*

\begin{tabular}{rcccc}
\hline & & \multicolumn{3}{c}{ Collision energy } \\
\cline { 3 - 5 } $\mathrm{m} / \mathrm{z}$ & lon & $6 \mathrm{eV}$ & $15 \mathrm{eV}$ & $20 \mathrm{eV}$ \\
\hline \hline 303 & $\mathrm{MH}^{+}$ & 100 & 22.5 & 2.1 \\
285 & $-\mathrm{H}_{2} \mathrm{O}$ & 1.2 & 3.9 & \\
232 & $\mathrm{y}_{3}$ & & 5.6 & 6.6 \\
214 & $\mathrm{~b}_{3}$ & 6.4 & 43.0 & 25.2 \\
169 & $\mathrm{a}_{3}^{*}$ & & 11.8 & 19.3 \\
161 & $\mathrm{y}_{2}$ & 11.4 & 100 & 100 \\
143 & $\mathrm{~b}_{2}$ & 1.5 & 38.4 & 85.0 \\
115 & $\mathrm{a}_{2}$ & & 8.3 & 29.7 \\
44 & $\mathrm{a}_{1}$ & & & 3.5 \\
\hline
\end{tabular}

${ }^{*} a_{3}^{*}=a_{3}-N_{3}$

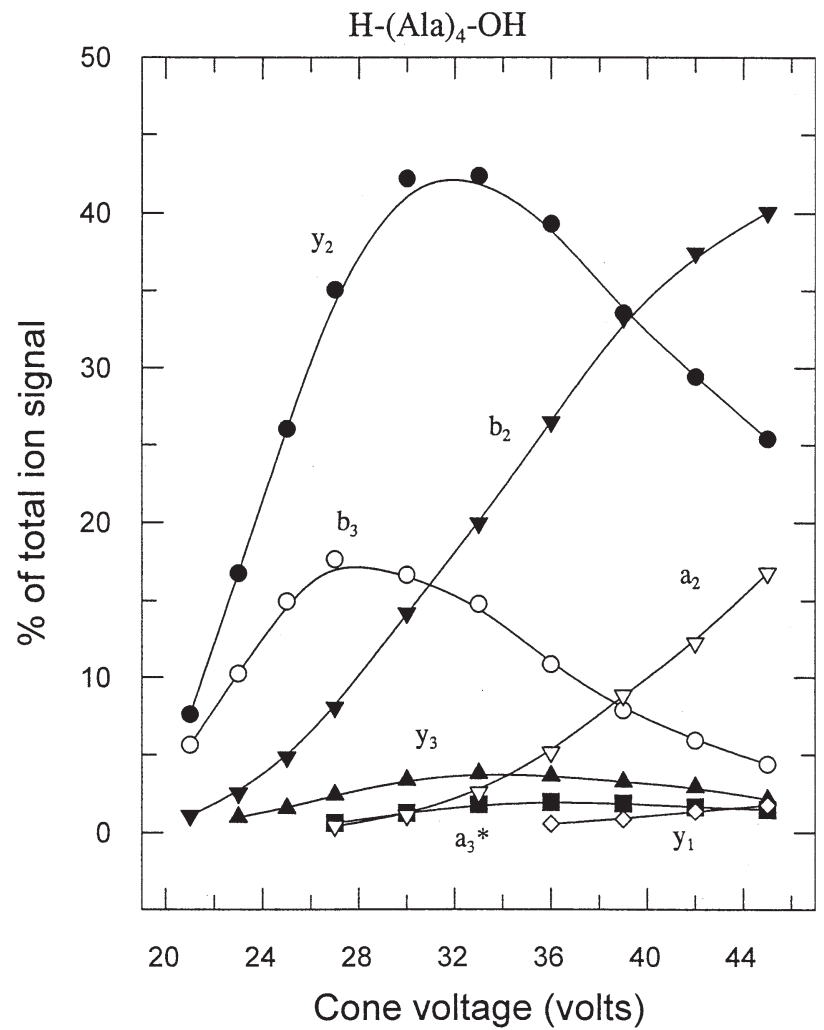

Figure 1. Breakdown graph for protonated tetraalanine obtained by cone-voltage CID. Ion signal for $\mathrm{MH}^{+}$not shown.

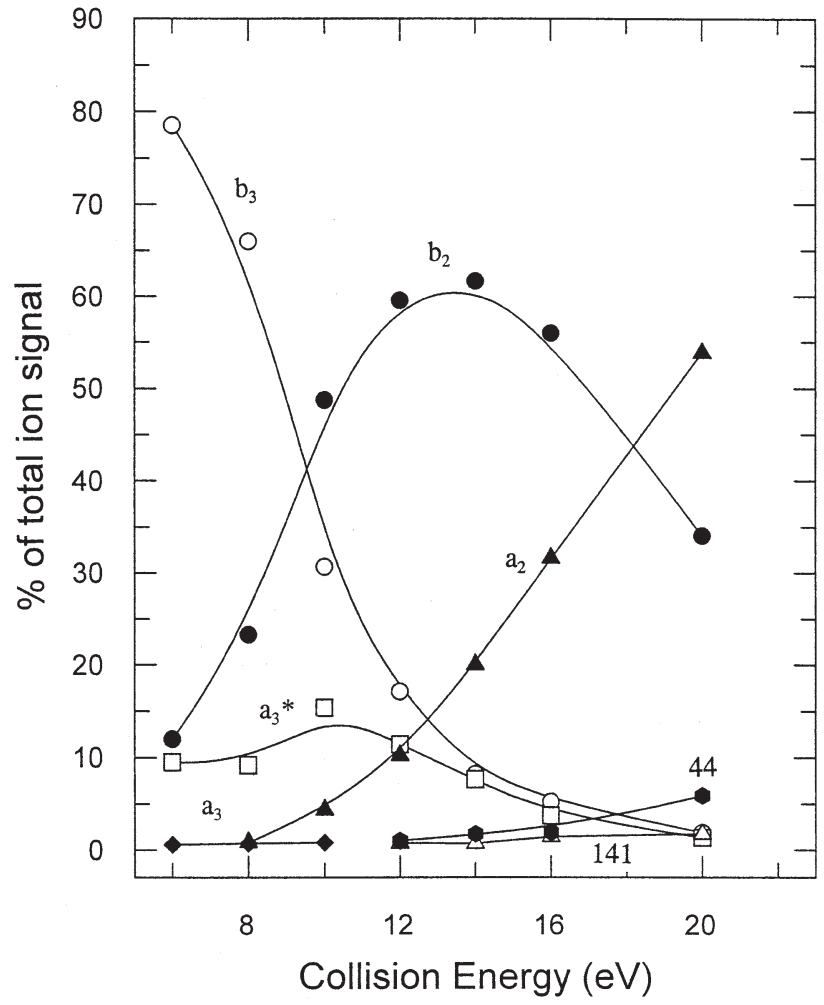

Figure 2. Breakdown graph for the $b_{3}$ ion derived from tetraalanine. 


\section{$\mathrm{H}-(\mathrm{Ala})_{5}-\mathrm{OH}$}
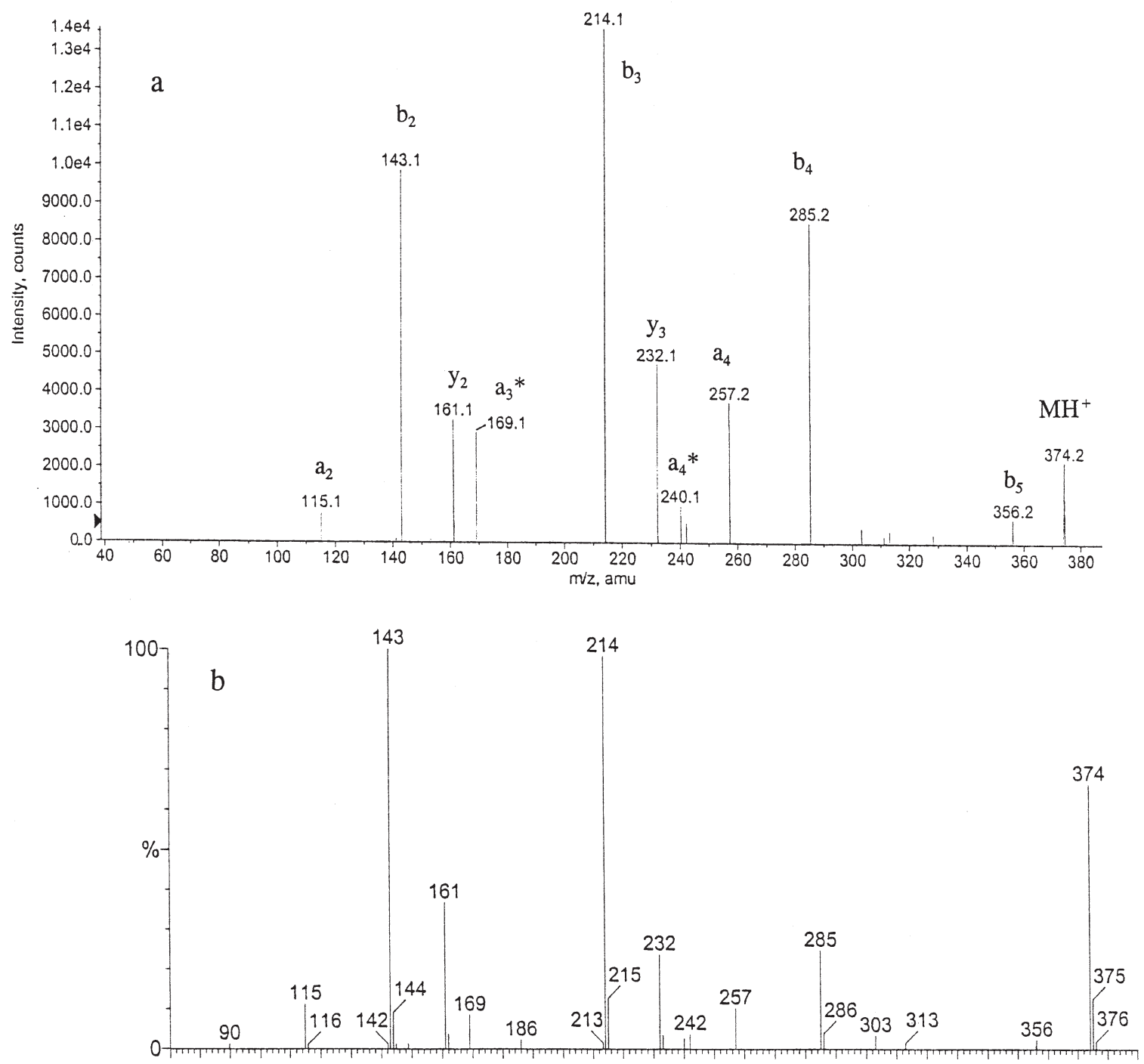

Figure 3. (a) CID mass spectrum of protonated pentaalanine obtained on QTOF at $20 \mathrm{eV}$ collision energy. $a_{x}^{*}=a_{x}-N_{3}$. (b) CID mass spectrum of protonated pentaalanine obtained by cone-voltage $\mathrm{CID}$ at $40 \mathrm{~V}$ cone voltage.

collision energies even though this is the thermochemically disfavored product; see below.) Figures 1 and 2 clearly indicate the reaction sequence $b_{3} \rightarrow b_{2} \rightarrow a_{2}$; this sequence is also evident from the breakdown graph obtained earlier [15] for protonated tetraalanine. Cleavage of the C-terminal amide bond leads to formation of the $b_{3}$ ion rather than the $y_{1}$ ion since the proton affinity of the corresponding oxazolone is $226.0 \mathrm{kcal} \mathrm{mol}^{-1}$ compared with $214.6 \mathrm{kcal} \mathrm{mol}^{-1}$ for alanine [29]. Similarly, cleavage of the central amide bond leads primarily to formation of the $y_{2}$ ion since PA(AA) $=225.4 \mathrm{kcal}$ $\mathrm{mol}^{-1}$ compared with $222.3 \mathrm{kcal} \mathrm{mol}^{-1}$ for the neutral oxazolone corresponding to the $b_{2}$ ion. An earlier metastable ion study of the fragmentation of the $b_{3}$ ion produced from pentaalanine showed formation of $a_{3}(81), a_{3}^{*}(100)$ and $b_{2}(71)$, where $a_{3}^{*}=a_{3}-N_{3}$; as shown in Figure 2, the $a_{3}$ ion is barely observed in the CID mass spectrum of the $b_{3}$ ion while the $a_{3}^{*}$ ion is observed in relatively low abundance. The formation of $a_{n}^{*}$ ions will be discussed in detail below.

\section{Pentaalanine}

Figure 3 compares the CID mass spectrum for protonated pentaalanine obtained with the QTOF instrument with that obtained by cone-voltage CID on the single quadrupole instrument. The spectra are quite similar and are in agreement with the spectra reported by Laskin and Futrell [27], particularly those obtained by surface-induced dissociation. The breakdown graph for 


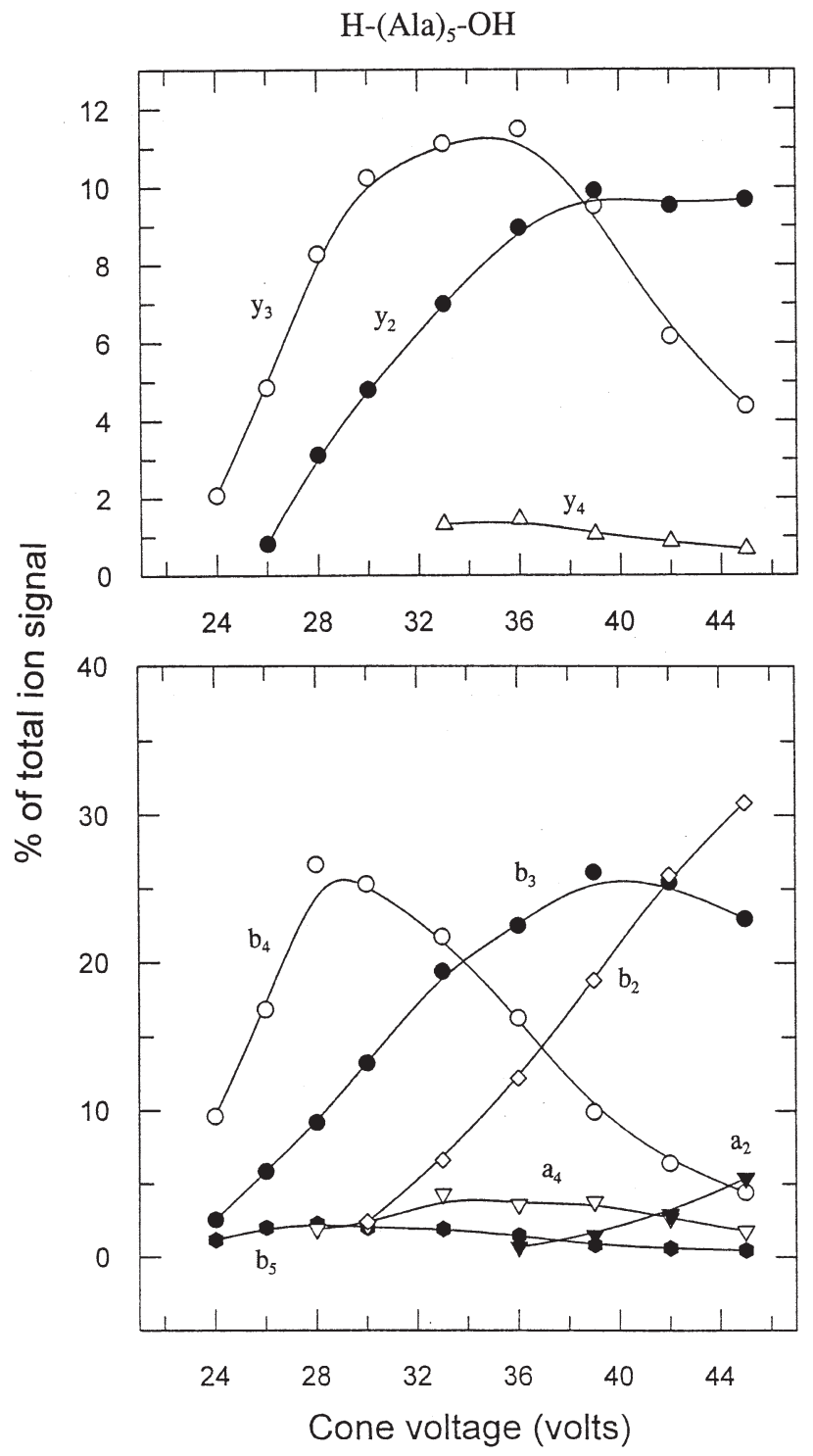

Figure 4. Breakdown graph for protonated pentaalanine obtained by cone-voltage CID. $\mathrm{MH}^{+}$ion signal not shown.

$\mathrm{MH}^{+}$obtained by cone-voltage CID is presented in Figure 4. Clearly, formation of $b_{4}$ is the most prominent fragmentation reaction with minor formation of $y_{3}, b_{3}$, $b_{5}\left(-\mathrm{H}_{2} \mathrm{O}\right)$, and $\mathrm{y}_{2}$. We believe that the apparent higher onset for the $\mathrm{y}_{2}$ product in Figure 4 is not real but reflects the detection limit for low-intensity ions. Metastable ion fragmentation of protonated pentaalanine showed $b_{5}(34), b_{4}(100), b_{3}(22), y_{3}(28)$, and $y_{2}(8)$ as fragmentation products [15]. If there was an equal propensity for cleavage of the various amide bonds, one would have expected the yields of $b_{3}, y_{3}$, and $y_{2}$ to be greater in both the metastable ion and lowest energy CID mass spectra. The dominance of the $b_{4}$ ion in both indicates that the C-terminal amide bond is preferentially cleaved. The calculations of Paizs and Suhai [29] have shown that the energy requirement for transfer of the proton from the most-favored amino position to the C-terminal amide nitrogen is lower than for transfer to
Table 3. Thermochemistry for fragmentation of protonated pentaalanine

\begin{tabular}{|c|c|c|c|}
\hline \multicolumn{2}{|c|}{$\mathrm{N}$-Terminus } & \multicolumn{2}{|c|}{ C-Terminus } \\
\hline Ion & $P A(\text { Neut })^{a}$ & Ion & $\mathrm{PA}(\text { Neut })^{a}$ \\
\hline $\mathrm{b}_{4}$ & 232.6 & $y_{1}$ & 214.6 \\
\hline$b_{3}$ & 226.0 & $y_{2}$ & 225.4 \\
\hline$b_{2}$ & 222.3 & $y_{3}$ & 233.1 \\
\hline
\end{tabular}

${ }^{\mathrm{a}} \mathrm{kcal} \mathrm{\textrm {mol } ^ { - 1 }}$

other amide nitrogens and that the energy requirement for cleavage of the C-terminal amide bond is lower than for cleavage of other amide bonds.

The primary fragmentation reactions of protonated pentaalanine can be rationalized in terms of the relative proton affinities of the respective products expected by the $b_{x}-y_{z}$ mechanism outlined in Scheme 2 and, indeed, provides support for the fragmentation mechanism. The proton affinities of the relevant oxazolones and amino acid/peptides, calculated by Paizs and Suhai [29], are presented in Table 3. Clearly, cleavage of the C-terminal amide bond will lead to formation of the $b_{4}$ ion since the $b_{4}$ oxazolone has a much higher proton affinity than that of alanine $\left(\mathrm{y}_{1}\right)$; this is what is observed in both metastable ion and CID mass spectra. On the other hand, cleavage of the next amide bond should lead to formation of both $b_{3}$ and $y_{2}$ ions since the proton affinities of the corresponding neutral are very similar; thus, both $b_{3}$ and $y_{2}$ are observed in metastable ion fragmentation. Cleavage of the $b_{2}-y_{3}$ bond should result in formation of the $y_{3}$ ion rather than the $b_{2}$ ion since the proton affinity of trialanine is considerably greater than that of the $b_{2}$ oxazolone. The dominance of the $b_{3}$ ion (with respect to the $y_{2}$ ion) and the abundant ion signal for the $b_{2}$ ion (Figure 3 ) arise from the dominant primary cleavage of the C-terminal amide bond to form the $b_{4}$ ion which fragments, in part, by the sequence $b_{4} \rightarrow b_{3} \rightarrow b_{2}$. This sequence is shown by the breakdown graph for the $b_{4}$ ion presented in Figure 5 . Formation of the $a_{4}$ ion (CO loss) and the $b_{3}$ ion are the major low-energy fragmentation routes of the $b_{4}$ ion; $a$ metastable ion study [15] of the $b_{4}$ ion showed $a_{4}(100)$, $b_{3}(38)$, and $b_{2}(7)$. It is evident that under CID conditions the $b_{3}$ ion is more readily formed. In the earlier study it was proposed that the neutral accompanying the $b_{n} \rightarrow$ $b_{n-1}$ fragmentation was a cyclic aziridinone, however, subsequent ab initio calculations [42, 43] have shown that this is a very energy-demanding route which cannot compete with the stepwise process $b_{n} \rightarrow a_{n} \rightarrow$ $b_{n-1}$. Thus, the detailed pathway for the direct $b_{n} \rightarrow$ $b_{n-1}$ reaction is not known; a possibility is outlined in Scheme 3 . That the reaction sequence $b_{4} \rightarrow a_{4} \rightarrow b_{3}$ does occur is shown by the formation of the $a_{4}$ ion from $b_{4}$ 


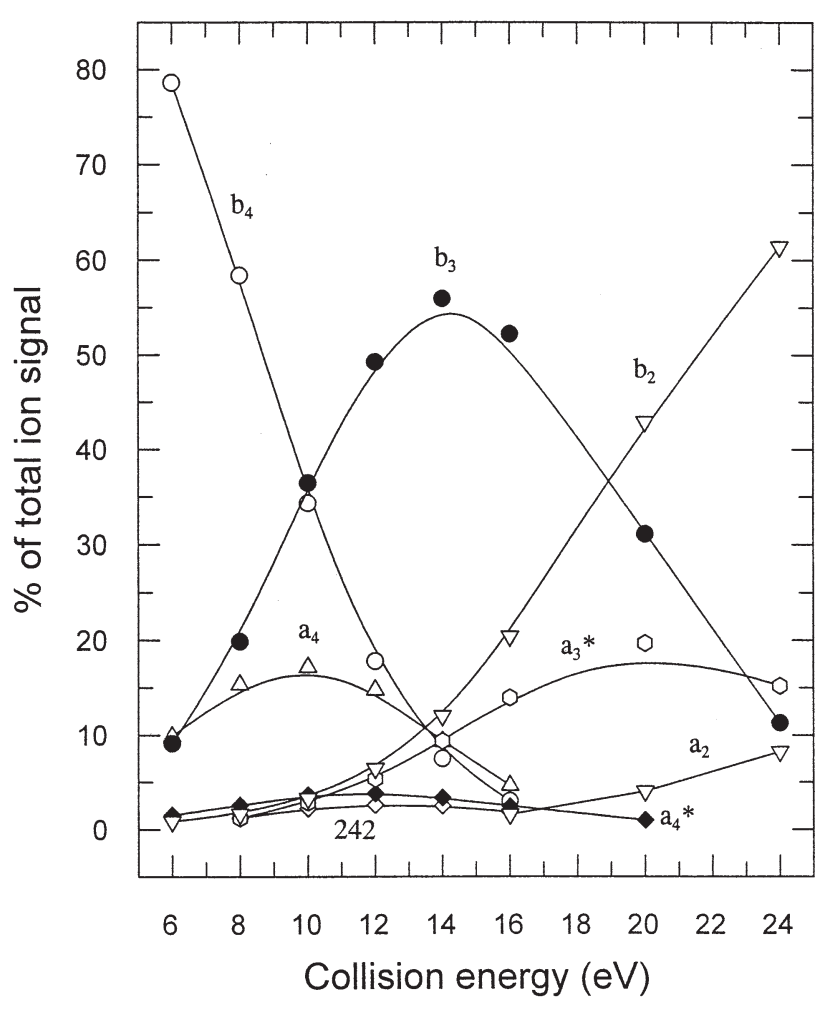

Figure 5. Breakdown graph for the $\mathrm{b}_{4}$ ion derived from pentaalanine.

(Figure 5) and by the breakdown graph for the $\mathrm{a}_{4}$ ion (Figure 6) which clearly shows the sequence $a_{4} \rightarrow b_{3} \rightarrow$ $b_{2} \rightarrow a_{2}$. The likely pathway for the $a_{n} \rightarrow b_{n-1}$ reaction is shown in Scheme 4. The other fragmentation pathway for the $\mathrm{a}_{4}$ ion is loss of $\mathrm{NH}_{3}$ to form the $\mathrm{a}_{4}^{*}$ ion. A prominent ion in the breakdown graph of Figure 6 is the $a_{3}^{*}$ ion which appears to be formed both by loss of an alanine residue from the $\mathrm{a}_{4}^{*}$ ion and by loss of $\mathrm{CO}+$ $\mathrm{NH}_{3}$ from the $b_{3}$ ion (see above). The $a_{3}^{*}$ fragments further by loss of $\mathrm{CO}$ to give $\mathrm{m} / \mathrm{z} 141$ with further minor loss of $\mathrm{CO}$ to give $\mathrm{m} / \mathrm{z} 113$. Possible routes to and structures of the $a_{n}^{*}$ ions are discussed later.

\section{Hexaalanine}

The CID mass spectrum of protonated hexaalanine, obtained on the QTOF instrument, is shown in Figure 7. The $b_{n}$ ion series dominates the mass spectrum with more minor $y_{n}$ ion series and $a_{n}$ ion series. Of particular note is the absence of the $a_{3}$ ion and the significant intensities for the $a_{n}^{*}$ series of ions. The breakdown graph for the $\mathrm{MH}^{+}$ion, obtained by cone-voltage CID, is shown in Figure 8. Clearly, the $b_{5}$ ion is the most

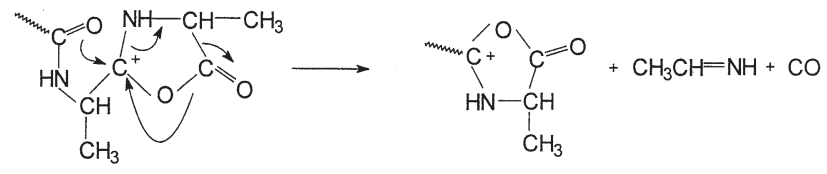

Scheme 3

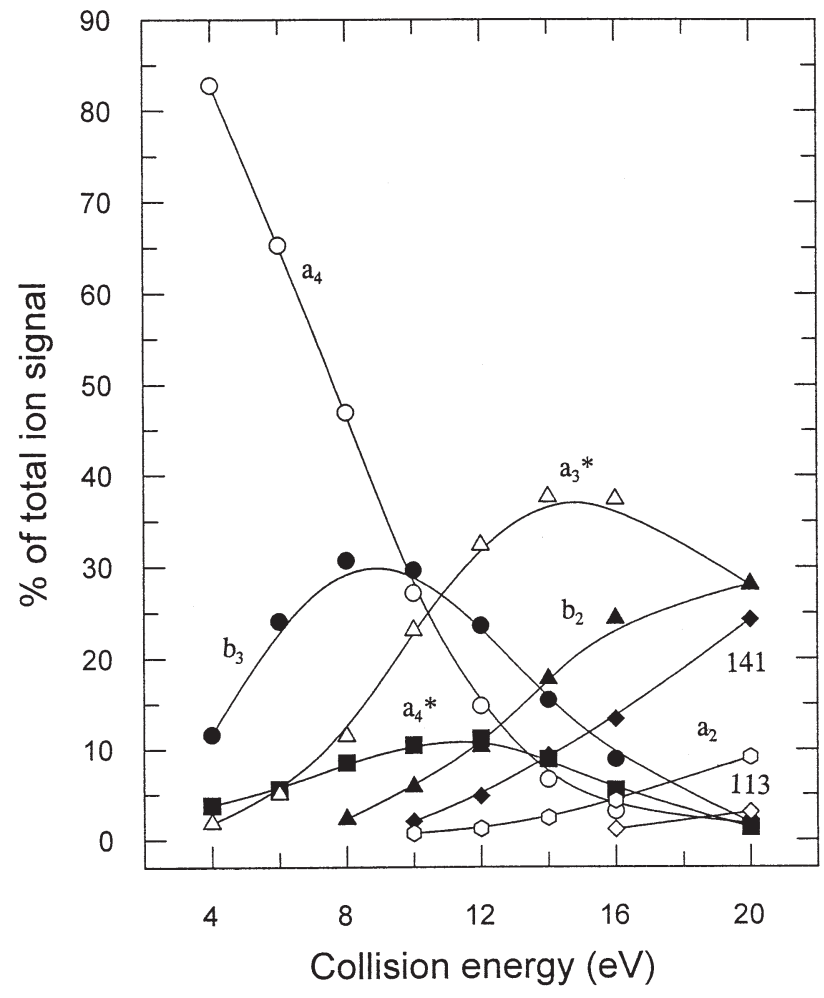

Figure 6. Breakdown graph for the $\mathrm{a}_{4}$ ion derived from pentaalanine.

abundant fragment ion at low collision energies with more minor yields of $b_{4}, y_{4}$, and $y_{3}$; the $y_{2}, b_{3}$, and $b_{2}$ ions are secondary products. Thermochemical data for fragmentation of protonated hexaalanine are presented in Table 4. (The proton affinities of the $b_{5}$ oxazolone and the $\mathrm{y}_{4}$ peptide have not been calculated and are assumed to be equal to or greater than those for the

$$
a_{n} \cdots-\cdots b_{n-1}
$$
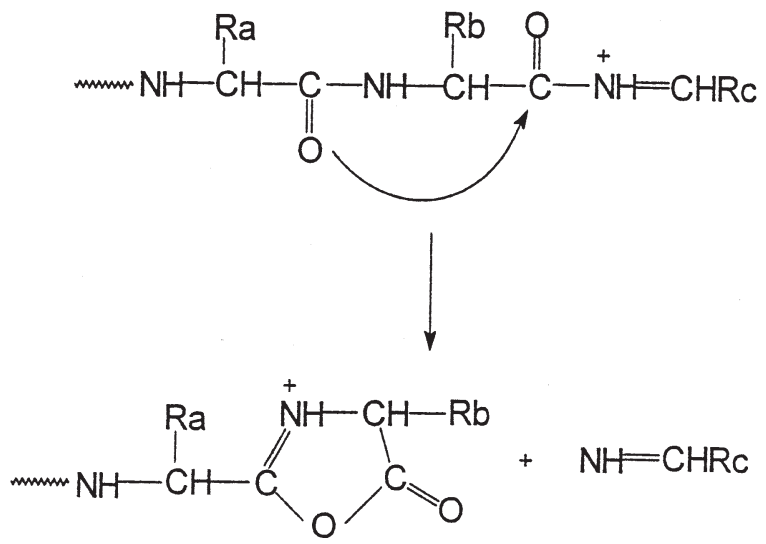

Scheme 4 


\section{$\mathrm{H}-(\mathrm{Ala})_{6}-\mathrm{OH}$}

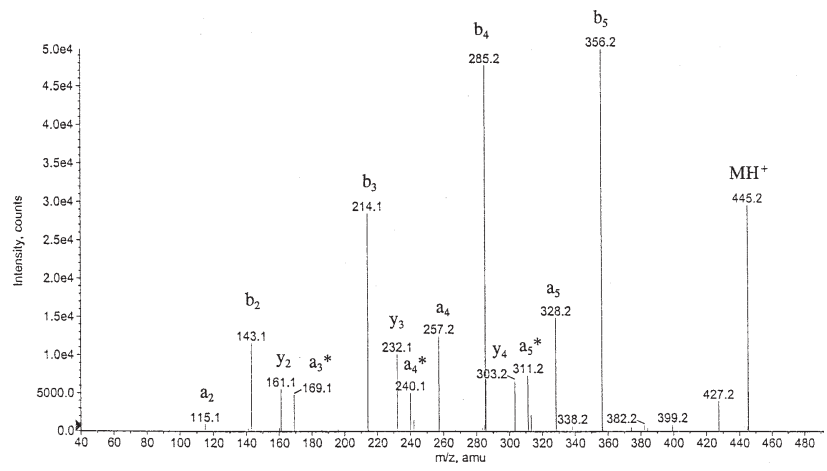

Figure 7. CID mass spectrum of protonated hexaalanine obtained on QTOF at $20 \mathrm{eV}$ collision energy.

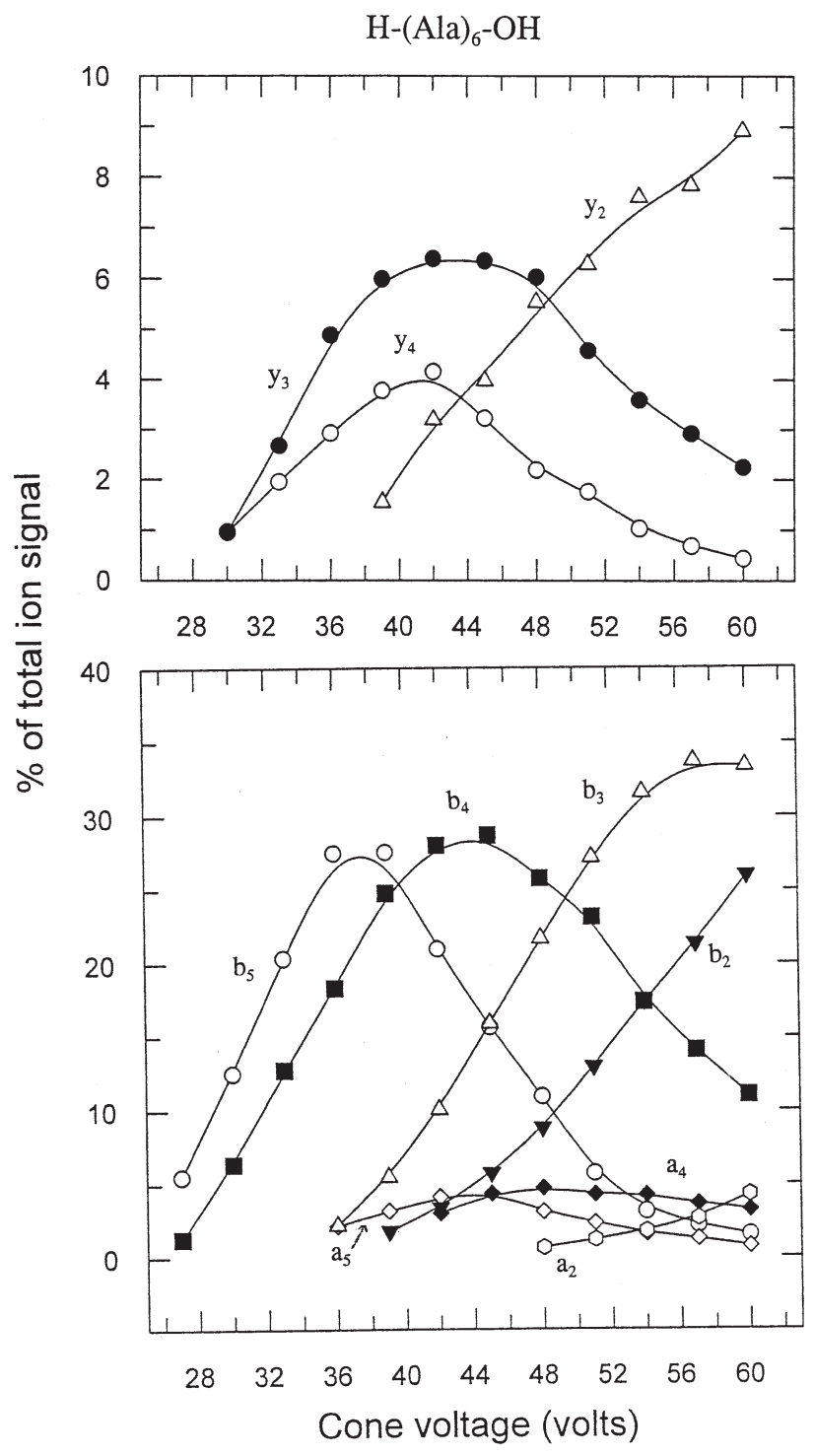

Figure 8. Breakdown graph for protonated hexaalanine obtained by cone-voltage CID.
Table 4. Thermochemistry for fragmentation of protonated hexaalanine

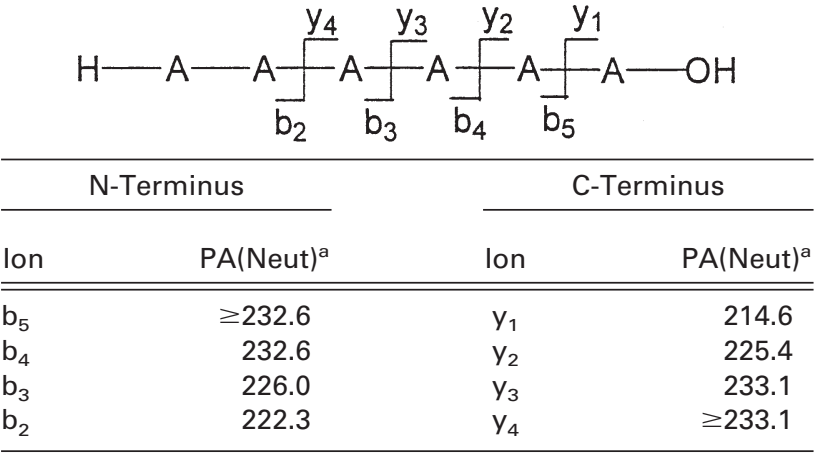

${ }^{\mathrm{a}} \mathrm{kcal} \mathrm{mol}{ }^{-1}$

homologous $b_{4}$ and $y_{3}$ species.) The thermochemical data indicate that formation of $b_{5}$ should be favored over formation of $y_{1}$, formation of $b_{4}$ favored over formation of $\mathrm{y}_{2}$ but formation of $\mathrm{y}_{3}$ and $\mathrm{y}_{4}$ should be favored over formation of the complimentary $b_{3}$ and $b_{2}$ ions; this is what is observed experimentally (Figure 8), thus providing support for the $b_{x}-y_{z}$ pathway outlined in Scheme 2. If there were an equal propensity for cleavage of the various amide bonds, one would expect to see more pronounced ion signals for $\mathrm{b}_{4}, \mathrm{y}_{4}$, and $\mathrm{y}_{3}$ at the lowest cone voltages; the relative dominance of the $b_{5}$ ion indicates that there is a preference for cleavage of the C-terminal amide bond as was observed for protonated pentaalanine.

The preferential cleavage of the C-terminal amide bond to form $b_{5}$ and the fragmentation sequence $b_{5} \rightarrow$ $b_{4} \rightarrow b_{3} \rightarrow b_{2}$, which is clearly shown by the breakdown graph for the $b_{5}$ ion (Figure 9), accounts for the dominance of the $b$ ion series in the CID mass spectrum of Figure 7. A second, more minor, fragmentation route for the $b_{5}$ ion forms the $a_{5}$ ion (CO loss) which initiates the fragmentation $a_{5} \rightarrow a_{4}$ and the sequence $a_{5} \rightarrow a_{5}^{*} \rightarrow$ $\mathrm{a}_{4}^{*} \rightarrow \mathrm{a}_{3}^{*}$, with the latter becoming a prominent product at higher collision energies. This fragmentation sequence is shown clearly by the breakdown graph for the $a_{5}$ ion (Figure 10) where the $a_{n}^{*}$ series of ions dominate the breakdown graph along with more minor formation of the $b_{4}$ ion as a primary fragmentation product. The origin of and possible structures of the $a_{n}^{*}$ ions are discussed below.

\section{Formation of $a_{n}^{*}$ Ions}

The CID mass spectra of protonated tetraalanine to hexaalanine show significant ion signals for $a_{n}^{*}\left(a_{n}-\right.$ $\mathrm{NH}_{3}$ ) ions. The only free amino group available to be lost as $\mathrm{NH}_{3}$ is the N-terminal amino function. Loss of this group in the absence of any rearrangement would lead to an electron-deficient carbocation [44] which is destabilized by the $\alpha$-carboxy group; such species are known [45-48] to have limited stability in the gas-phase and we suggest that cyclization has occurred upon loss 


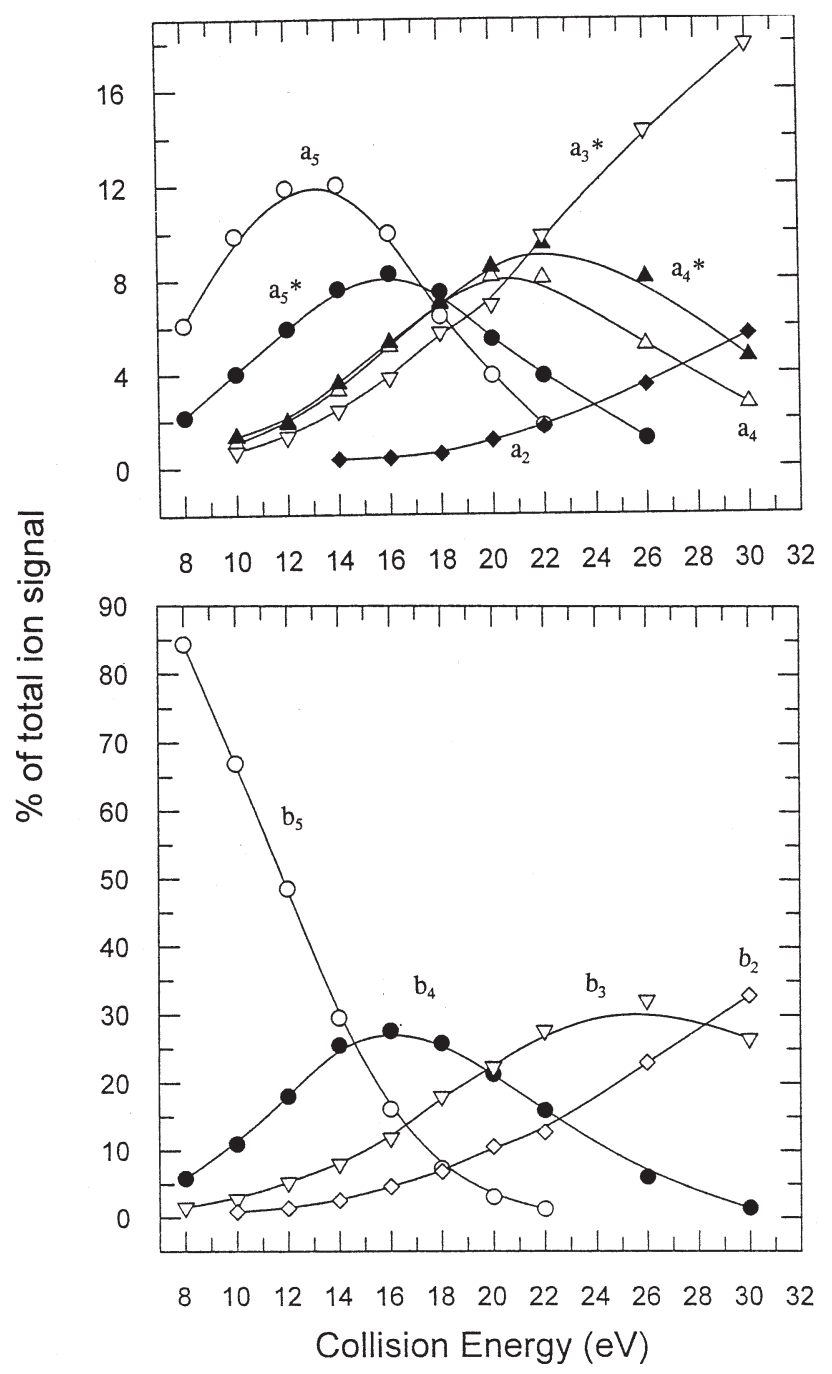

Figure 9. Breakdown graph for the $b_{5}$ ion derived from hexaalanine.

of $\mathrm{NH}_{3}$. The most straightforward case is the formation of the $a_{3}^{*}$ ion in the mass spectrum of protonated tetraalanine. Earlier metastable ion studies [15] indicate the reaction sequence $\mathrm{MH}^{+} \rightarrow \mathrm{b}_{3} \rightarrow \mathrm{a}_{3} \rightarrow \mathrm{a}_{3}^{*}$; under CID conditions, the last step appears to be particularly facile since the $a_{3}$ ion abundance is very low in the CID mass spectrum. In Scheme 5 we propose a pathway for the $a_{3}$ $\rightarrow a_{3}^{*}$ reaction leading to a cyclic structure which might be expected to lose $\mathrm{CO}$ on further fragmentation, as observed experimentally.

The breakdown graph for the $a_{5}$ ion derived from hexaalanine (Figure 10) clearly shows the reaction sequence $a_{5} \rightarrow a_{5}^{*} \rightarrow a_{4}^{*} \rightarrow a_{3}^{*}$, i.e., the initial loss of $N_{3}$ is followed by sequential loss of two alanine residues resulting in formation of the stable $\mathrm{a}_{3}^{*}$ ion. It is not clear whether the $a_{5}^{*}$ and $a_{4}^{*}$ species are cyclic or remain in the acyclic form; certainly, if they are larger cyclic ions they must open to accommodate the loss of the alanine residues.

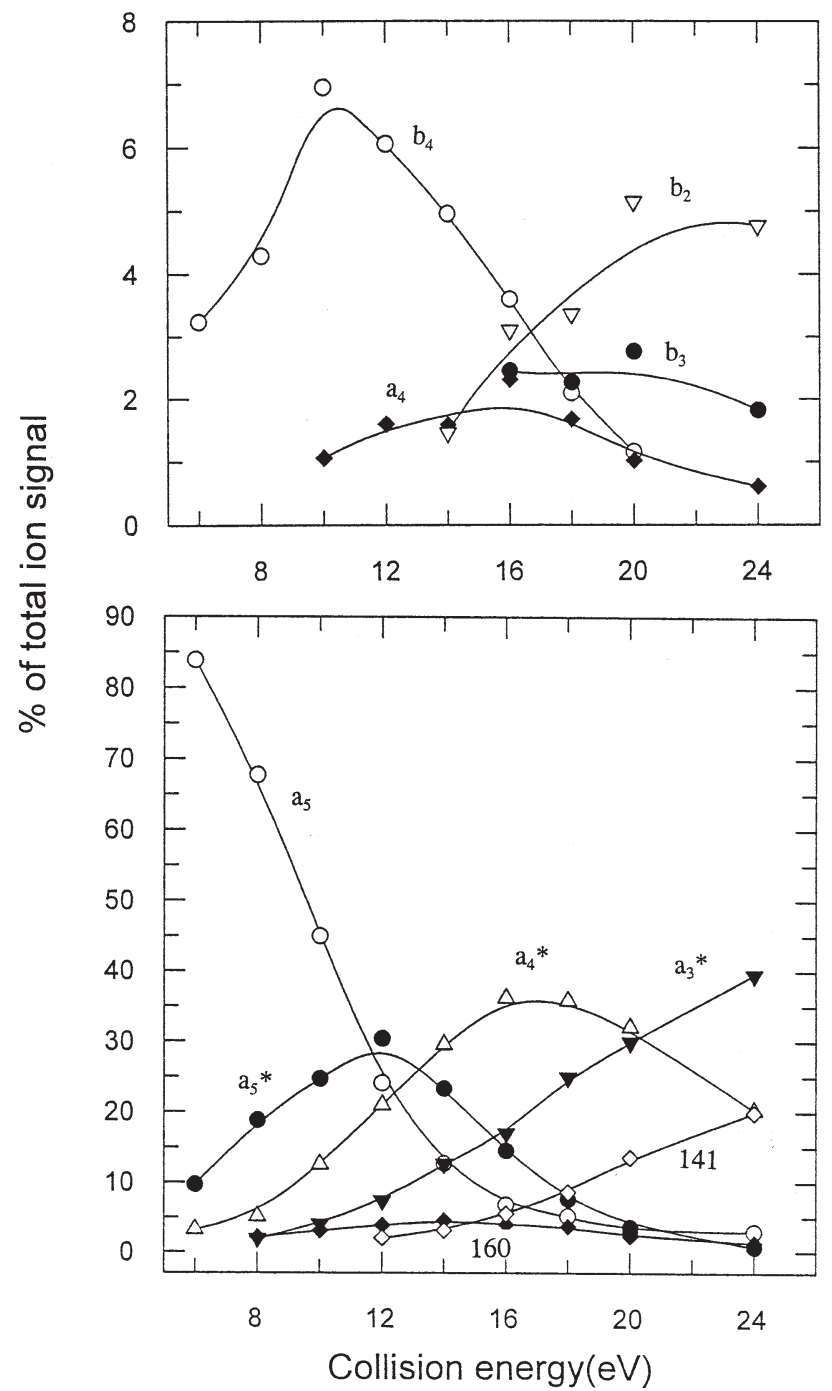

Figure 10. Breakdown graph for the $b_{5}$ ion derived from hexaalanine.

\section{Conclusions}

The primary fragmentation reactions of the protonated oligoalanines involve cleavage of an amide bond to produce $b_{\mathrm{x}}$ or $\mathrm{y}_{\mathrm{z}}$ ions. The present work has shown that the primary fragmentation reactions can be adequately rationalized in terms of the $b_{x}-y_{z}$ pathway outlined in Scheme 2, with the relative abundances of the $b_{x}$ and $y_{z}$ ions being determined by the relative proton affinities of the corresponding neutral oxazolones and peptides/ amino acid. The results thus provide strong support for the fragmentation mechanism outlined in Scheme 2. For protonated pentaalanine and protonated hexaalanine there is a distinct preference for primary fragmentation by cleavage of the C-terminal amide bond to form the respective $\mathrm{b}$ ion. The majority, if not all, of the lower mass $b$ ions originate by sequential fragmentation of the $b_{n}$ ion formed by cleavage of the C-terminal amide bond. The major fragmentation pathway for the oligoalanines is the sequence $b_{n} \rightarrow b_{n-1} \rightarrow b_{n-2}$ with a 
<smiles>CC[NH2+]C(=O)C(C)NC(=O)C(C)N</smiles><smiles>CC1NC(=O)C(C)([NH3+])C(=O)N(C)C1C</smiles><smiles>CCN1C(=O)C(C)NC(=O)[C@H]1C</smiles>

Scheme 5

minor contribution from the sequence $b_{n} \rightarrow a_{n} \rightarrow b_{n-1}$. The fact that most of the lower mass $b$ ions are secondary products has significant implications for the conditions used to record CID mass spectra, if one wishes to observe the complete series of $\mathrm{b}$ ions, which are often of major importance in peptide sequencing. The behavior observed for the oligoalanines will undoubtedly change when amino acids with different functionalities are present in the peptide, since they will affect not only the favored site of amide nitrogen protonation but also the relative proton affinities of the oxazolones and peptides which will be reflected in the products formed by amide bond cleavage. In addition, they likely will have a distinct influence on the relative importance of the $b_{n} \rightarrow$ $b_{n-1} \rightarrow b_{n-2}$ and $b_{n} \rightarrow a_{n} \rightarrow b_{n-1}$ pathways. These aspects are under study in our laboratory.

\section{Acknowledgments}

This work was supported by the Natural Sciences and Engineering Council (Canada) through a research grant to AGH and an equipment grant to the Department of Chemistry which made possible the purchase of the QStar. AGH is indebted to Dr. B. Paizs for helpful discussions and the communication of results prior to publication.

\section{References}

1. Whitehouse, C. M.; Dreyer, R. N.; Yamashita, M.; Fenn, J. B. Electrospray Interface for Liquid Chromatographs and Mass Spectrometers. Anal. Chem. 1985, 57, 675.

2. Electrospray Ionization Mass Spectrometry. Fundamentals, Instrumentation, and Applications; Cole, R. B., Ed.; Wiley: New York, 1997.

3. Applied Electrospray Mass Spectrometry; Pramanik, B. N.; Ganguly, A. K.; Gross, M. L., Eds.; Marcel Dekker: New York, 2002.

4. Karas, M.; Hillenkamp, F. Laser Desorption Ionization of Proteins with Molecular Masses Exceeding 1000 Daltons. Anal. Chem. 1988, 60, 2299.

5. Beavis, R. C.; Chait, B. T. Matrix-Assisted Laser DesorptionIonization Mass Spectrometry of Proteins. Methods Enzymol. $1996,270,519$.

6. Tandem Mass Spectrometry; McLafferty, F. W., Ed.; Wiley: New York, 1983.

7. Busch, K. L.; Glish, G. L.; McLuckey, S. A. Mass Spectrometry/ Mass Spectrometry: Techniques and Applications of Tandem Mass Spectrometry; VCH: New York, 1988.

8. Roepstorff, P.; Fohlman, J. Proposal for a Common Nomenclature for Sequence Ions in Mass Spectra of Peptides. Biomed. Mass Spectrom. 1984, 11, 601.

9. Biemann, K. Contributions of Mass Spectrometry to Peptide and Protein Structure. Biomed. Env. Mass Spectrom. 1988, 16, 99.

10. Biemann, K. Sequencing of Peptides by Tandem Mass Spectrometry and High-Energy Collision-Induced Dissociation. Methods Enzymol. 1990, 193, 455.

11. Papayannopoulos, I. A. The Interpretation of Collision-Induced Dissociation Tandem Mass Spectra of Peptides. Mass Spectrom. Rev. 1995, 14, 49.

12. Mueller, D. R.; Eckersley, M.; Richter, W. Hydrogen Transfer Reactions in the Formation of " $Y+2$ " Sequence Ions from Protonated Peptides. Org. Mass Spectrom. 1988, 23, 217.

13. Cordero, M. M.; Houser, J. J.; Wesdemiotis, C. The Neutral Products Formed During Backbone Fragmentation of Protonated Peptides in Tandem Mass Spectrometry. Anal. Chem. 1993, 65, 1594.

14. Yalcin, T.; Khouw, C.; Csizmadia, I. G.; Peterson, M. R.; Harrison, A. G. Why are B Ions Stable Species in Peptide Mass Spectra? J. Am. Soc. Mass Spectrom. 1995, 6, 1165.

15. Yalcin, T.; Csizmadia, I. G.; Peterson, M. R.; Harrison, A. G. The Structures and Fragmentation of $B_{n}(n \geq 3)$ Ions in Peptide Mass Spectra. J. Am. Soc. Mass Spectrom. 1996, 7, 293.

16. Nold, M. J.; Wesdemiotis, C.; Yalcin, T.; Harrison, A. G. Amide Bond Dissociation in Protonated Peptides. Structures of the N-Terminal Ionic and Neutral Fragments. Int. J. Mass Spectrom. Ion Processes. 1997, 164, 137.

17. Paizs, B.; Lendvay, G.; Vékey, K.; Suhai, S. Formation of $b_{2}{ }^{+}$ Ions from Protonated Peptides. An ab Initio Study. Rapid Commun. Mass Spectrom. 1999, 13, 525.

18. Harrison, A. G.; Csizmadia, I. G.; Tang, T.-H. Structures and Fragmentation of $\mathrm{b}_{2}$ Ions in Peptide Mass Spectra. J. Am. Soc. Mass Spectrom. 2000, 11, 427.

19. Rodriquez, C. F.; Shoeib, T.; Chu, I. K.; Siu, K. W. M.; Hopkinson, A. C. Comparison Between Protonation, Lithiation, and Argentination of 5-Oxazolones. A Study of a Key Intermediate in Gas-Phase Peptide Sequencing. J. Phys. Chem. A 2000, 104, 5355.

20. Farrugia, J. M.; Taverner, T.; O'Hair, R. A. J. Side-Chain Involvement in the Fragmentation Reactions of the Protonated Methyl Esters of Histidine and Its Peptides. Int. J. Mass Spectrom. 2001, 209, 99.

21. Farrugia, J. M.; O'Hair, R. A. J.; Reid, G. E. Do All b ${ }_{2}$ Ions Have Oxazolone Structures? Mass Spectrometry and ab Initio Stud- 
ies on Protonated N-Acyl Amino Acid Methyl Ester Model Systems. Int. J. Mass Spectrom. 2001, 210/211, 71.

22. Ambihapathy, K.; Yalcin, T.; Leung, H.-W.; Harrison, A. G. Pathways to Immonium Ions in the Fragmentation of Protonated Peptides. J. Mass Spectrom. 1997, 32, 209.

23. EL, Aribi, H.; Rodriquez, C. F.; Almeida, D. R. P.; Ling, Y.; Mak, W. W.-N.; Hopkinson, A. C.; Siu, K. W. M. Elucidation of Fragmentation Mechanisms of Protonated Peptide Ions and Their Products: A Case Study on Glycylglycylglycine Using Density Functional Theory and Threshold Collision-Induced Dissociation. J. Am. Chem. Soc. 2003, 125, 9229.

24. Yeh, R. W.; Grimsley, J. M.; Bursey, M. M. Collisionally Induced Fragmentation of Protonated Oligoalanines and Oligoglycines. Biol. Mass Spectrom. 1991, 20, 443.

25. Schwartz, B. L.; Bursey, M. M. Some Proline Substituent Effects in the Tandem Mass Spectrum of Protonated Pentaalanine. Biol. Mass Spectrom. 1992, 21, 92.

26. Laskin, J.; Denisov, E.; Futrell, J. Comparative Study of Collision-induced and Surface-Induced Dissociation. 2. Fragmentation of Small Alanine-Containing Peptides in FT-ICR MS. J. Phys. Chem. B 2001, 105, 1895.

27. Laskin, J.; Denisov, E.; Futrell, J. Fragmentation Energetics of Small Peptides from Multiple-Collision Activation and Surface-Induced Dissociation in FT-ICR MS. Int. J. Mass Spectrom. 2002, 219, 189.

28. Laskin, J.; Futrell, J. Surface-Induced Dissociation of Peptides: Kinetics and Dynamics. J. Am. Soc. Mass Spectrom. 2003, 14, 1340.

29. Paizs, B.; Suhai, S. Towards Understanding the Tandem Mass Spectra of Protonated Oligopeptides 1: Mechanism of Amide Bond Cleavage. J. Am. Soc. Mass Spectrom. 2004, 15, 103.

30. Harrison, A. G. Energy-Resolved Mass Spectrometry. A Comparison of Quadrupole Cell and Cone Voltage CollisionInduced Dissociation, Rapid Commun. Mass Spectrom. 1999, 13, 1663.

31. van Dongen, W. D.; van Wijk, J. I. T.; Green, B. M.; Heerma, W.; Haverkamp, J. Comparison Between Collision Induced Dissociation of Electrosprayed Protonated Peptides in the Up-Front Region and in a Low-Energy Collision Cell. Rapid Commun. Mass Spectrom. 1999, 13, 1712.

32. Harrison, A. G. Fragmentation Reactions of Alkylphenyl Ammonium Ions. J. Mass Spectrom. 1999, 34, 1253.

33. Makowiecki, J.; Tolonen, A.; Uusitalo, J.; Jalonen, J. Cone Voltage and Collision Cell Collision-Induced Dissociation of Triphenylethylenes of Pharmaceutical Interest. Rapid Commun. Mass Spectrom. 2001, 15, 1506.

34. Buré, C.; Lange, C. Comparison of Dissociation of Ions in an Electrospray Source or a Collision Cell in Tandem Mass Spectrometry. Curr. Org. Chem. 2003, 7, 1613.
35. McLuckey, S. A.; Cooks, R. G. Angle- and Energy-Resolved Fragmentation from Tandem Mass Spectrometry. In Tandem Mass Spectrometry; McLafferty, F. W., Ed.; Wiley: New York, 1983; p 203.

36. Smith, R. D.; Loo, J. A.; Barinaga, C. J.; Edmonds, C. G.; Udseth, H. R. Collisional Activation and Collision-Activated Dissociation of Large Multiply Charged Polypeptides and Proteins Produced by Electrospray Ionization. J. Am. Soc. Mass Spectrom. 1990, 1, 53.

37. Chen, H.; Tabei, K.; Siegel, M. M. Biopolymer Sequencing Using a Triple Quadrupole Mass Spectrometer in the ESI Nozzle-Skimmer/Precursor Ion MS/MS Mode. J. Am. Soc. Mass Spectrom. 2001, 12, 846.

38. Paizs, B.; Suhai, S. Combined Quantum Chemical and RRKM Modeling of the Main Fragmentation Pathways of Protonated GGG. II. Formation of $\mathrm{b}_{2}, \mathrm{y}_{1}$ and $\mathrm{y}_{2}$ Ions. Rapid Commun. Mass Spectrom. 2002, 16, 375.

39. Paizs, B.; Suhai, S. Towards Understanding Some Ion Intensity Relationships for the Tandem Mass Spectra of Protonated Peptides. Rapid Commun. Mass Spectrom. 2002, 16, 1699.

40. Paizs, B.; Suhai, S.; Harrison, A. G. Experimental and Theoretical Investigation of the Main Fragmentation Pathways of Protonated H-Gly-Gly-Sar-OH and H-Gly-Sar-Sar-OH. J. Am. Soc. Mass Spectrom. 2003, 14, 1454.

41. Paizs, B.; Suhai, S. Fragmentation Pathways of Protonated Peptides. Mass Spectrom. Rev., in press.

42. Fang, D.-C.; Yalcin, T.; Tang, T.-H.; Fu, X.-Y.; Harrison, A. G., Csizmadia, I. G. Electron Distribution in Cationic Fragments Generated Mass Spectrometrically from Peptides. J. Mol. Struct. (Theochem.) 1999, 468, 135.

43. Tang, T.-H.; Fang, D.-C.; Harrison, A. G.; Csizmadia, I. G. A Computational Study of the Fragmentation of $b_{3}$ Ions Derived from Protonated Peptides. J. Mol. Struct. (Theochem.) 2004, 675, 79 .

44. Gassman, P. G.; Tidwell, T. T. Electron-Deficient Carbocations. Acc. Chem. Res. 1983, 16, 279.

45. Grutzmacher, H.-F.; Dommröse, A.-M. Kinetic Energy Release During CO Loss by Rearrangement of $\alpha$-Benzoylcarbenium Ions. Org. Mass Spectrom. 1983, 18, 601.

46. Dommröse, A.-M.; Grutzmacher, H.-F. Destabilized Carbenium Ions. Secondary and Tertiary $\alpha$-Acetylbenzyl Cation and $\alpha$-Benzoylbenzyl Cation. Org. Mass Spectrom. 1987, 22, 437.

47. Wolf, R.; Grutzmacher, H.-F. Destabilized Carbenium Ions. $\alpha$-Carbomethoxy- $\alpha, \alpha$-Dimethylmethyl Cation. Org. Mass Spectrom. 1989, 24, 398.

48. Tkaczyk, M.; Harrison, A. G. Formation of Destabilized Carbenium Ions by Charge Inversion of Negative Ions. Int. J. Mass Spectrom. Ion Processes 1991, 109, 295. 